\title{
Advanced Anticorrosion Coatings Prepared from Polybenzoxazine/ $\alpha$-zirconium Phosphate Nanocomposites
}

\author{
Shuliang Li, Chunxia Zhao , Haolan Gou, Yuntao Li ${ }^{*}$, Xiaojia He, Ling Zhao \\ College of Materials Science and Engineering, Southwest Petroleum University, Chengdu 610050, \\ China \\ *E-mail: polychem2011@hotmail.com(C. Zhao), yuntaoli@swpu.edu.cn (Y. Li)
}

doi: $10.20964 / 2018.03 .76$

Received: 16 November 2017 / Accepted: 21 January 2018 / Published: 5 February 2018

\begin{abstract}
In this study, we present the first successful application of polybenzoxazine/ $\alpha$-zirconium phosphate $(\mathrm{PBa} / \alpha-\mathrm{ZrP})$ nanocomposites for corrosion protection. $\alpha-\mathrm{ZrP}$ nanoplatelets were exfoliated by a polyetheramine surfactant (Jeffamine M1000), and the $\alpha-Z r P$ dispersed well in the PBa matrix with no substantial agglomeration. $\mathrm{PBa} / \alpha-\mathrm{ZrP}$ composite coatings were also prepared on the carbon steel substrate, and their anticorrosive properties were investigated in $3.5 \mathrm{wt} \% \mathrm{NaCl}$ solution via electrochemical impedance spectroscopy and polarization curves. The results reveal that welldispersed $\alpha$-ZrP nanoplatelets in the PBa matrix effectively enhanced the corrosion protection ability of the coatings, attributing to the extended diffusion path of the corrosive agents in the coating to reach to the protected metal surface. The samples with $5 \mathrm{wt} \% \alpha-\mathrm{ZrP}$ nanoplatelets showed a corrosion rate of $0.108 \mathrm{~mm}$ per year for carbon steel after 8-day immersion, and the corrosion rate was less than half of that of the neat pristine PBa sample. These results of this study reveal that the incorporation of $\alpha-\mathrm{ZrP}$ in the PBa matrix efficiently improved the corrosion protection of the PBa composite.
\end{abstract}

Keywords: Polybenzoxazines; $\alpha$-zirconium phosphate; Nanocomposite coatings; Anticorrosion

\section{FULL TEXT}

(C) 2018 The Authors. Published by ESG (www.electrochemsci.org). This article is an open access article distributed under the terms and conditions of the Creative Commons Attribution license (http://creativecommons.org/licenses/by/4.0/). 